\title{
Effect of Six Weeks of Swimming Training on Malondialdehyde and Superoxide Dismutase Levels in the Heart Tissue of Mice with Breast Cancer
}

Behnaz Vanaky (PhD)

Department of Physical Education and Sport Sciences, Islamic Azad University, Science and Research Branch, Tehran, Iran

Nader Shakeri (PhD)

Department of Physical Education and Sport Sciences, Islamic Azad University, Science and Research Branch, Tehran, Iran

Hojat Allah Nikbakht (PhD) Department of Physical Education and Sport Sciences, Islamic Azad University, Science and Research Branch, Tehran, Iran

Parvin Farzanegi (PhD)

Department of Exercise

Physiology, Islamic Azad

University, Sari Branch, Sari, Iran

Corresponding author: Nader

Shakeri

Tel: +982144865154

Email: nsprofsport@gmail.com

Address: Department of Physical Education and Sport Sciences،

Faculty of Humanities and Social

Sciences, Islamic Azad University,

Science and Research Branch,

Tehran, Iran

Received : 31 Jan 2018

Revised: 02 Apr 2018

Accepted: 17 Apr 2018

Behnaz Vanaky 0000000278952074 Nader Shakeri 0000000272079681

Parvin Farzanegi https://orcid.org/0000-0003-2182 Parvin
3068
ABSTRACT

Background and Objectives: Breast cancer is one of the most common cancers among women. Cardiovascular disease is one of the most important complications of breast cancer. The aim of this study was to investigate the effects of six weeks of swimming on malondialdehyde (NIDA) and superoxide dismutase (SOD) levels in the heart tissue of mice with breast cancer.

Method: Breast cancer was induced in 30 female Balb/c mice (6-8 weeks old, weighing 150-200 g) by tumor transplantation. The tumor site was examined every day for the formation or absence of tumor. After becoming familiar with the laboratory environment and swimming pool, the subjects were randomly divided into three equal groups: 1. healthy control, 2. cancer control, and 3. swimming-cancer. The swimming group performed swimming training 60 minutes/day, five days a week, for six weeks. After the intervention, the levels of SOD and $\mathrm{VIDA}$ in the heart tissue samples were evaluated by enzyme-linked immunosorbent assay. Data were analyzed in SPSS (version 16) using independent t-test at significance of 0.05 .

Results: The results showed that induction of breast cancer was accompanied by a significant increase in MIDA and a significant decrease in S0D in the heart tissue of mice. Participation in the six-week swimming significantly reversed these effects.

Conclusion: Swimming could have beneficial effects in improving oxidative factors in breast cancer patients.

Keywords: Breast Neoplasms, Heart, Malondialdehyde, Superoxide Dismutase, Swimming.

This paper should be cited as: Vanaky B, Shakeri N, Nikbakht HA, Farzanegi P[Effect of Six Weeks of Swimming Training on Malondialdehyde and Superoxide Dismutase Levels in the Heart Tissue of Mice with Breast Cancer]. mliaoums. 2018; 12(3):24-29 


\section{INTRODUCTION}

Breast cancer is one of the most common cancers in females making up $28.9 \%$ of all cancers and $17.6 \%$ of mortalities among women worldwide (1). Studies show that inheritance and environmental factors such as diet and physical activity are the risk factors for breast cancer $(2,3)$. Patients with breast cancer typically suffer from multiple diseases such as diabetes, obstructive pulmonary disease, heart disease, arthritis and hypertension (3). Evidence suggests that cardiovascular disease is a main complication of breast cancer before, during and after chemotherapy (4). Left ventricular dysfunction might be a long-term complication of chemotherapy in patients with breast cancer. However, evidence shows that breast cancer survivors have increased risk of myocardial infarction and coronary artery disease (5). Nevertheless, it is not clear whether breast cancer itself can cause cardiovascular complications before chemotherapy.

Oxidative stress has been prominently known to cause DNA damage, alter signaling pathways, and affect progression of various types of cancer (6). Free radicals are highly reactive due to presence of unpaired electrons in their molecular orbitals. They can cause cell death by targeting different cell components, especially the plasma and organelle membranes (7). The imbalance between production of free radicals and antioxidant defense in the living body results in oxidative stress, which plays a significant role in pathogenesis of various diseases (8).

Malondialdehyde (MDA) is a highly reactive dialdehyde produced via peroxidation of unsaturated fatty acid in the human body. Amount of lipid peroxidation could be evaluated by measuring MDA levels in different biological samples, which can be used as a marker of oxidative stress (9). MDA affects the function of molecules and cells and exerts carcinogenic, mutagenic and atherogenic effects by reacting with purines. ROS produces MDA, which deactivates the membrane carriers and promotes carcinogenic effects (10). Increasing evidence supports the role of oxidative stress in the development of various types of cancer. In addition, presence of high levels of MDA in breast tissue of breast cancer patients could be useful for gaining a better understanding of the mechanisms involved in breast cancer (11).
The most important antioxidant enzyme in all aerobic organisms is superoxide dismutase (SOD), which play a direct role in the reduction of active metabolites. Cell proliferation, angiogenesis, inflammation, and cell death pathways are often involved in SOD-mediated cancer prevention (12). Therefore, there seems to be a strong relationship between the level of antioxidant enzymes, especially SOD, and breast cancer progression. Various studies have shown that SOD level in breast cancer patients is lower than that in healthy individuals. This might indicate the potential of the enzyme for treatment of cancer and estimation of patient's survival $(6,13)$. It has been reported that some types of exercise such as moderate endurance training could increase SOD activity (14). However, a few studies reported that 14 weeks of endurance training did not affect SOD (15, 16). In another study, 21 weeks of strengthendurance training showed a significant increase in SOD in middle-aged males (17). It has been also demonstrated that resistance training is more effective in increasing MDA levels compared to low intensity resistance training (11). Moreover, it has been shown that supplementation and regular exercise in water could reduce IL-6 and MDA levels in patients with breast cancer (18).

Although cardiovascular disease has been reported in patients with breast cancer after chemotherapy, evaluation of oxidative stress markers in the heart tissue before chemotherapy seems essential. There are numerous studies on the effects of exercise on the factors associated with oxidative stress. Although physical activity seems to adjust exercise capacity, no study has yet shown that exercise activity can reduce the effects of markers of oxidative stress and increase antioxidants level in the heart tissue of patients with breast cancer. Therefore, the purpose of this study was to evaluate the effect of six weeks of swimming on MDA and SOD levels in the heart tissue of mice with breast cancer and healthy control mice.

\section{MATERIAL AND METHODS}

This experimental study was done on 30 Balb/c female mice (6-8 weeks old) weighing 150-200g, which were purchased from the Pasteur Institute, Iran. After induction of 
breast cancer, the subjects were familiarized with the environment and performed swimming exercise in a pool for a week. The mice were randomly divided into three groups (10 mice in each group): 1. swimming-cancer, 2. cancer control, and 3. healthy control. All procedures were carried out in accordance with the regulations and recommendations for the care and use of laboratory animals. The subjects were kept separately and in transparent polycarbonate cages (dimensions: $15 \times 15 \times 30 \mathrm{~cm}$, purchased from Razi Rad Co.) with 12:12-h light:dark cycle, ambient temperature of $22 \pm 2{ }^{\circ} \mathrm{C}$ (humidity $50 \pm 5 \%$ ) and proper ventilation. At all stages of the study, adequate food and water were provided for the subjects. After anesthetizing the mice, tumor mass was rapidly excited under sterile conditions and washed three times with sterile phosphate buffer solution. Subsequently, all mice were anesthetized with intraperitoneal injection of $100 \mathrm{mg} / \mathrm{Kg}$ ketamine (Rotexmedia, Germany and $10 \mathrm{mg} / \mathrm{Kg}$ xylazin (Bayer Co., South Korea), and a small section $(5 \mathrm{~mm})$ of breast cancer tumor was implanted subcutaneously in the upper femur region as described in a previous study (19). After tumor implantation, the tumor site was examined every day for the formation or absence of tumor (20). After ensuring the development of breast cancer (21), the swimming group mice were placed freely inside the pool. They instinctively swam in the water after being placed in the water from the neck to the bottom. Duration of this procedure was ten minutes on the first day and increased by five minutes every day. After total activity time reached 60 minutes on day 11 , the subjects performed swimming exercise 60 minutes/day for six weeks $(20,22,23)$. Forty hours after the last session and following 10-12 hours of fasting, all subjects were anesthetized by intraperitoneal injection of ketamine (100 $\mathrm{mg} / \mathrm{Kg}$ body weight) and zylasein $(10 \mathrm{mg} / \mathrm{Kg}$ body weight). After opening the chest, heart was immediately removed from the aortic root. After washing the heart tissue with distilled water and accurate weighing, the tissue were kept in a freezer at $80{ }^{\circ} \mathrm{C}$. The levels of SOD and MDA in the heart tissues were measured using enzyme-linked immunosorbent assay kits (Ziegler, Germany) according to the manufacturer's instructions. Descriptive statistics were used to analyze the data and Shapiro-Wilk test was used to evaluate data distribution. Independent t-test was performed at statistical significance of 0.05 . All statistical analyses were performed in SPSS (version 16). The study protocol received approval from the ethics committee of Islamic Azad University, Science and Research Branch, Tehran (IR.IAU.SRB.REC.1395.37).

\section{RESULTS}

After the six-week intervention, the weight of the mice increased in all groups (Table 1). However, this increase was less significant in the swimming-cancer group compared to the other groups. On the other hand, the volume of the tumor in the Swimming-cancer group had increased, that it was lower than Cancer-control group.

Table 1- Changes of the weight and tumor volume in the study groups at baseline and after the intervention

\begin{tabular}{ccccc}
\hline Groups & \multicolumn{2}{c}{ Weight $(\mathrm{g})$} & \multicolumn{2}{c}{ Tumor Volume $\left(\mathrm{cm}^{3}\right)$} \\
\cline { 2 - 5 } & First week & After 6 weeks & First week & After 6 weeks \\
Healthy-Control & 17.43 & 21.57 &.-- & 0.061 \\
Cancer-Control & 17.83 & 21.71 & 0.052 & 0.536 \\
Swimming-Cancer & 17.71 & 20.86 & 0.049 & 0. \\
\hline
\end{tabular}

shown in figures 1 and 2, the cancer control group had significantly higher MDA level and significantly lower SOD level compared to the healthy control group $(\mathrm{P}<0.05)$.

Figure1- Comparison of MDA levels between the healthy control and cancer control groups

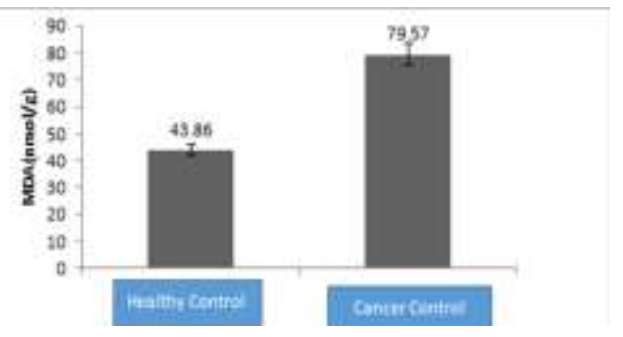


Figure 2- Comparison of SOD levels between the healthy control and cancer control groups

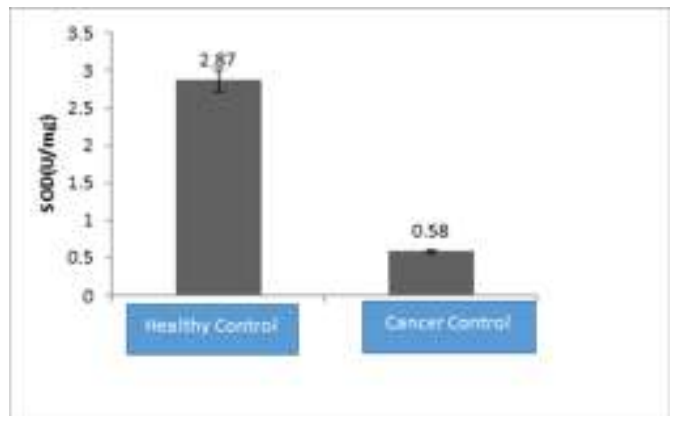

The results showed that six weeks of swimming reduced MDA level by $33.56 \%$ in the heart tissue of mice with breast cancer compared to the control group (Figure 3). In addition, SOD level in the heart tissue of mice in the swimming-cancer group increased by $318.7 \%$ compared to those in the cancer control group (Figure 4).

Figure 3- MDA level in the cancer control and swimming-cancer groups after six weeks of swimming

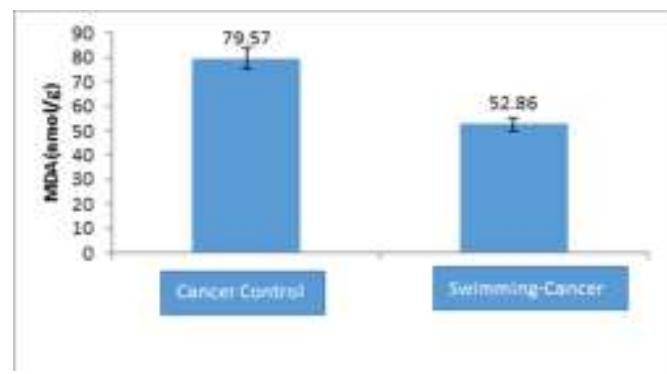

Figure 4- SOD level in the cancer control and swimming-cancer groups after six weeks of swimming

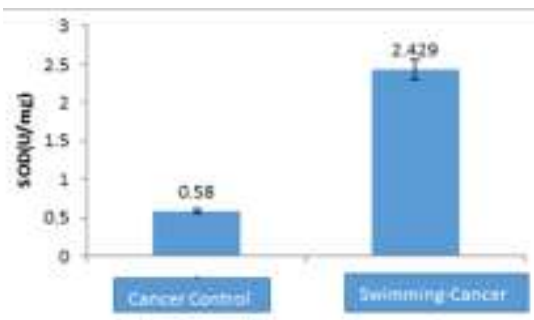

\section{DISCUSSION}

In the present study, induction of breast cancer increased MDA level $(81.41 \%)$ as the oxidative factor and reduced SOD $(79.79 \%)$ as the antioxidant factor compared to the healthy control group. The results suggest that breast cancer may alter heart tissue oxidative factors that could lead to cardiovascular complications. Meanwhile, the results showed that six weeks of swimming significantly increased SOD levels in the heart tissue of mice with breast cancer. Results of studies on the SOD level in breast cancer patients have been inconsistent $(11,13,17)$. These studies have investigated SOD levels in blood, tumor, and muscle and liver samples, while we measured SOD in the heart tissue of mice with breast cancer.

Consistent with our results, some studies reported that moderate exercise and endurance training significantly increase SOD levels (24, 25). However, a number of studies reported the opposite $(15,16,26)$. This difference in the results could be due to the type, intensity and duration of the exercise performed by the subjects.

It can be concluded that exercise activity improves mitochondrial function in the skeletal and heart muscles, resulting in 
increased SOD level and decreased free radicals generation and oxidative stress, which all contribute to reduced risk of heart disease in breast cancer (27).

In the present study, MDA level decreased significantly $(33.56 \%)$ in the heart tissue of mice with breast cancer after six weeks of swimming. This is in agreement with the results of other studies $(11,18)$, which showed that regular swimming and moderate intensity aerobic exercise can increase resistance against ROS-induced lipid peroxidation and reduce accumulation of oxidized proteins and DNA damage (25). Inconsistent with our findings, some studies have shown that athletes who perform aerobic and anaerobic exercise have higher MDA levels. This difference can be due to variation in the fitness and physical readiness of the subjects. Previous studies on combined exercise training also reported an increase in MDA levels after

\section{REFERENCES}

1. Ferlay J, Autier P, Boniol M, Heanue M, Colombet M

, Boyle P. Estimates of the cancer incidence and mortality in Europe in 2006. Ann Oncol. 2007; 18(3): 581-592.

2. Ripperger T, Gadzicki D, Meindl A, Schlegelberger B. Breast cancer susceptibility: current knowledge and implications for genetic counseling. European Journal of Human Genetics. 2008; 17(6): 722-731. doi: 10.1038/ejhg.2008.212.

3. Song M, Lee KM, Kang D. Breast cancer prevention based on gene-environment interaction. Molecular carcinogenesis. 2011; 50(4): 280-290. doi: 10.1002/mc.20639.

4. Sturgeon KM, Ky B, Libonati JR, Schmitz KH. The effects of exercise on cardiovascular outcomes before, during, and after treatment for breast cancer. Breast Cancer Res Treat. 2014; 143(2): 219-226.

5. Khan NF, Mant D, Carpenter L, Forman D, Rose PW. Long-term health outcomes in a British cohort of breast, colorectal and prostate cancer survivors: a database study. Br J Cancer. 2011; 105 Suppl 1:S29-37. doi: 10.1038/bjc.2011.420.

6. Lee JD, Cai Q, Shu XO, Nechuta SJ. The role of biomarkers of oxidative stress in breast cancer risk and prognosis: A systematic review of the epidemiologic literature. J. Women's Health. 2017; 26(5): 467-482. doi: 10.1089/jwh.2016.5973.

6. Valko M, Leibfritz D, Moncol J, Cronin MT, Mazur M, Telser J. Free radicals and antioxidants in normal physiological functions and human disease. Int $\mathrm{J}$ Biochem Cell Biol. 2007; 39(1): 44-84.

7. Finaud J, Lac G, Filaire E. Oxidative stress: relationship with exercise and training. Sports Medicine J. 2006; 36(4): 327-58. exercise (29). It can be concluded that the effect of exercise on oxidative stress markers depends on the exercise intensity and duration.

\section{CONCLUSION}

Our results show that six weeks of swimming can modify oxidative factors, which might be effective in prevention of cardiovascular complications in breast cancer patients.

\section{ACKNOWLEDGEMENTS}

This article has been derived from a $\mathrm{PhD}$ thesis by Dr. Behnaz Vanaky, registered at Iranian Research Institute for Information Science and Technology (No. 3946296).

\section{CONFLICT OF INTEREST}

All contributing authors declare that there is no conflict of interest.

8. Karimi N, Dabidi V, Ayaz A. The effect of Water Based Exercise and Ginger Supplements on Myocardium and Systemic Stress in Obese Women with Breast Cancer. Olympic Journal. 2013; 21(3): 19-34.

9. Taghiyar S, Shahani Poor K, Razmi NA. Comparison of the Serum Level of Carcinoembryonic antigen, Prolactin, and Malondialdehyde in Patients Suffering from Breast Cancer and in Healthy individuals in Isfahan. Journal of Fasa University of Medical Sciences. 2014; 4(3): 362-370.

10. Nevin Atalay Güzel, Serkan Hazar, Deniz Erbas. Effects of different resistance exercise protocols on nitric oxide, lipid peroxidation and creatine kinase activity in sedentary males. Journal of Sports Science and Medicine. 2007; 6(4): 417-422.

11. Robbins Delira, Zhao Yunfeng, Manganese Superoxide Dismutase in Cancer Prevention Antioxidants \& Redox Signaling. 2014 Apr 1; 20(10): 1628-1645. doi: 10.1089/ars.2013.5297.

12. Negahdar M, Djalali M, Abtahi H, Sadeghi MR, Aghvami T, Javadi E, et al. Blood superoxide dismutase and catalase activities in women affected with breast cancer. Iranian J Publ Health. 2005; 34(3): 39-43.

13. Goon JA, Aini AH, Musalmah M, Anum MY, Nazaimoon WM, Ngah WZ. Effect of Tai Chi exercise on DNA damage, antioxidant enzymes, and oxidative stress in middle-age adults. J Phys Act Health. 2009; 6(1): 4354.

14. Marsh SA, Laursen PB, Coombes JS. Effects of antioxidant supplementation and exercise training on erythrocyte antioxidant enzymes. Int J Vitam Nutr Res. 2006; 76(5): 324-331. 


\section{9/Vanaky and colleagues}

15. Lambertucci RH, Levada-Piresa AC, Rossonia LV, Curia R, Pithon-Curi TC. Effects of aerobic exercise training on antioxidant enzyme activities and $m R N A$ levels in soleus muscle from young and aged rats. Mech Ageing Dev. 2007; 128(3): 267-75. DOI:10.1016/j.mad.2006.12.006.

16. García-López D, Häkkinen K, Cuevas MJ, Lima E, Kauhanen A, Mattila M, et al. Effects of strength and endurance training on antioxidant enzyme gene expression and activity in middle-aged men. Scand J Med Sci Sports. 2007; 17(5): 595-604.

17. Fathi Bayyatiani Z, Dabidi Roshan V, Ayaz A, Hoseinzadeh M. The relationship between proinflammatory markers and lipid per oxidation after water-based regular exercise and ginger supplementation in patients with breast cancer. Scientific-Research Journal of Shahed University.2013; 20(104): 61-76. [Persian]

18. Heydarieh N, Faraji M. Ginger Ethanolic effects on body weight and breast cancer tumor growth in mice. female BALB /C. Animal Research J. 2015; 27(4): 487497. [Persian]

19. Barari A, Farzanegi P, Bashiri J, Abbassi Daloii A, Kochpideh F, Gholami F. Effect of 6 weeks of swimming training and aloe vera extract supplementation on the serum levels of Cyclooxygenase-2 and vascular endothelial growth factor in mice with breast cancer. Qom Univ. Med Sci. J. 2017; 11(7): 12-20. [Persian]

20. De Oliveira F, Maifrino LB, De Jesus GP, Carvalho JG, Marchon C, Ribeiro DA. The Role of Cytoxygenase 2 On Endurance Exercise Training in female $L D L$ Receptor Knockout Overiectomized mice. Anais da Academia Brazilaria de Giencias. 2013; 85(3): 1157-64.

21. Barari A, Bashiri J, Asgari J. The effect of a six-week swimming training program combine with Aloe vera extract on human epidermal growth factor receptor 2 and estrogen and progesterone receptors in mice with breast cancer. Feyz, Journal of Kashan University of Medical Sciences. 2015; 19(5):382-90.
22. Kazemi AR, Agha Alinejad H, Rasul Eslami, Ehsan $\mathrm{P}$, Baghaie $\mathrm{R}$, Dabaghzadeh $\mathrm{R}$, et al. Investigating the Effect of Endurance Training on Tumor Level of IL-8 and Serum Level of IL-17 in Female Mice with Breast Cancer. Journal of Fasa University of Medical Sciences. Autumn 2015; Vol.5 (3)347-355.

23. Hatao H, Oh-ishi S, Itoh M, Leeuwenburgh C, Ohno $\mathrm{H}$, Ookawara $\mathrm{T}$, et al. Effects of acute exercise on lung antioxidant enzymes in young and old rats. Mech Ageing Dev. 2006; 127(4): 384-390.

24. Rahbar S, Ahmadiasl N. Effect of long term regular resistance exercise on heart function and oxidative stress in rats. Journal of Ardabil University of Medical. 2012; 12(3): 256-264.

25. Souza-Rabbo MP, Silva LF, Auzani JA, Picoral M, Khaper N, Belló-Klein A. Effects of a chronic exercise training protocol on oxidative stress and right ventricular hypertrophy in monocrotaline-treated rats. Clin Exp Pharmacol Physiol. 2008; 35(8): 944-8. doi: 10.1111/j.1440-1681.2008.04936.x.

26. Powers SK, Jackson MJ. Exercise-Induced Oxidative Stress: Cellular Mechanisms and Impact on Muscle Force Production. Physiological reviews. 2008;88(4):1243-1276. doi: 10.1152/physrev. 00031 . 2007.

27. Park SY, Kwak YS. Impact of aerobic and anaerobic exercise training on oxidative stress and antioxidant defense in athletes. J Exerc Rehabil. 2016; 12(2):113118.Doi: $10.12965 /$ jer.1632598.299.

28. Delavar $\mathrm{R}$, Mogharnasi $\mathrm{M}$, Khoobkhahi N. The effects of combined training on oxidative stress and antioxidant defense indicators. Int. J Basic Sci. Med. 2017; 2(1):29- 32. doi :10.15171/ ijbms.2017.07. 